\title{
Making Fiscal Policy Flexibly Independent of Government
}

\author{
Nicholas Gruen
}

The art of good government is to constantly review practices to see where improvements can be made. The guiding principles should be to design systems that make it clear what the medium-term goals are, to choose goals that can be communicated easily to the public and accepted as being reasonable, and to ensure that the system is transparent so that people can judge whether policy changes are consistent with the goals. (Ian Macfarlane, Governor of the Reserve Bank Australia, 1996)

$\mathrm{E}$ CONOMIC reform consists not only of achieving desired economic outcomes but also of building economic institutions that systematically improve the chances that desired economic outcomes will be achieved in the future. Unfortunately, the first of these tasks often displaces the second. Yet institutional reform can have large and long-lasting benefits.

Institutional reform frequently involves distancing some area of economic activity from the day-to-day workings of government. The Industries Assistance Commission (IAC), established in 1974, is the paradigm example in Australia. While it remained a strictly advisory body, it exerted a strong influence on policy. Its rationale was that it offset the invidious incentives that governments faced: the few individuals who stood to benefit greatly from industry assistance were well organised and capable of exerting considerable political pressure, while the many who stood to lose were poorly organised politically and often unaware of their losses.

Other economic reforms have reflected a similar rationale. For example, the corporatisation of government business enterprises has distanced governments from day-to-day commercial decisions; and over the last two decades the Reserve Bank of Australia has built up respect for its independence and its much enhanced role in managing monetary policy. Would institutional reform likewise improve the management of fiscal policy? In this article a possible reform to the institutions of fiscal policy is outlined, which would help guard against fiscal irresponsibility at the same time as substantially improving the scope for fiscal policy to be used in the management of the economic cycle.

Nicholas Gruen is an Assistant Commissioner with the Industry Commission. The views expressed are those of the author alone. 
The central problem is that fiscal expansion is generally more politically popular than contraction, which generates a bias towards expansion. ${ }^{1}$ There are at least three ways (not all of them mutually exclusive) to constrain a government's control of fiscal policy: to develop institutions which maximise the transparency of fiscal policy; to distance government from the management of fiscal policy; and to establish and/or constitutionally entrench rules governing the conduct of fiscal policy. The first and third of these options have attracted most attention. Yet in the area of monetary policy the second approach has been most prominent: in several countries monetary authorities either control or heavily influence the management of monetary policy with some degree of independence from government.

\section{Mandating Fiscal Transparency}

New Zealand's Fiscal Responsibility Act and the Australian Charter of Budget Honesty take the first of the three courses set out above by mandating increased fiscal policy transparency. One important objective of the New Zealand legislation has been to use public transparency 'to tilt the balance of fiscal decision-making away from the short-term economic and political considerations that have been influential in the past and towards strategic and long-term fiscal objectives' (Scott, 1995:3). Likewise, Australia's National Commission of Audit (1996:278) suggested that a Charter of Budget Honesty would 'provide a useful counterbalance against spending pressures'. But, as Ruth Richardson, a former Minister of Finance in New Zealand, has conceded (1994:10), New Zealand's fiscal responsibility legislation 'places an onus on the government to be explicit about its fiscal strategy, but is neutral as to what that fiscal stance might be'. Within a few years of its implementation in the 1980 s, the fiscal effects of former US President Reagan's policies were fully transparent, but had little apparent effect in constraining those policies.

\section{Mandating Fiscal Rules}

The third option - constraining government by means of certain established fiscal policy rules - is embodied in various proposals for balanced budget requirements to be established in legislation and/or entrenched constitutionally. But such a response may be worse than the disease, however serious. Such rules can be evaded: a government may be able to conform to the letter of such provisions while subverting their spirit by various accounting and regulatory practices (Keese, 1985:158). And even if legislated rules could be enforced, it is not clear that they should be. Rigid requirements to balance budgets are likely to exacerbate, perhaps gravely, the volatility of the business cycle. During a recession, policy-makers would not only be prevented from engineering discretionary fiscal expansion; they would be required actively to tighten fiscal policy to counteract the effect of the economy's automatic stabilisers. The case against rigid rules was well put by Blinder and Solow (1974:45):

\footnotetext{
${ }^{1}$ I concede below that this claim is something of a simplification, but it serves satisfactorily as a basis of discussion at this stage of the exposition.
} 
The best that can be said for rules is that some of them may be better than incompetently managed discretionary policy if that is the only kind of discretionary policy the nation can get. But ... the institutions that produce perverse discretionary policy might equally well produce perverse rules, and follow them only spasmodically.

\section{Arrangements for Flexible Independence}

The second of the three options listed above has received so little attention possibly because no mechanism is immediately evident which could deliver to fiscal policy the kind of flexible independence which characterises monetary policy institutions. For instance, having explained how the instruments of New Zealand's economic policy were being progressively removed from direct government control, Bollard (1994:12) comments, 'It is more difficult to envisage how fiscal policy could be carried out at arms length from government, given the exigencies of stabilisation and spending needs'. Scott (1995:15) is more emphatic:

Fiscal decision making, in contrast [to monetary policy], goes to the very heart of a government's development strategy and political priorities, and cannot be delegated [to a central agency such as the Reserve Bank] in the same way. Only the implementation of detailed fiscal decisions can be delegated.

Yet one can envisage institutional mechanisms which distance the determination of the overall stance of fiscal policy from day-to-day government by analogy with modern economic institutions in areas such as industry assistance and monetary policy. To do so, an independent statutory agency would be necessary with expertise in fiscal policy: let us call it the Central Fiscal Authority (CFA). Equally necessary is an instrument with which the stance of fiscal policy can be changed quickly and simply. This is the rate at which taxes are levied. It would be possible to provide for arrangements such that tax rates specified in existing legislation could be made a function of a parameter, which we will call the 'taxation parameter'. ${ }^{2}$

To simplify for the sake of example, suppose that existing legislation sets corporate tax at a flat rate of 30 per cent, personal tax at the same rate subject to a tax-free threshold of $\$ 5,000$, and wholesale taxes at a uniform rate of 20 per cent. To introduce the scheme being outlined here, legislation would be enacted which would specify that the effective tax rate to be charged would be the legislated rate multiplied by the taxation parameter which would initially be set at 1 . As the new arrangements were introduced, it would become possible to vary the taxation parame-

\footnotetext{
${ }^{2}$ The exposition here abstracts somewhat from the complications of federal government. The existence of State governments with their own fiscal positions would, if it were brought into the analysis, complicate exposition without adding a great deal. Of course, there might be some merit in applying the kind of arrangements mooted here at the State level, but it would not be necessary to do so for them to have a powerful effect when applied at the Commonwealth level.
} 
ter away from its initial value with consequent effects on tax rates - and so, other things being equal, the stance of fiscal policy. Table 1 illustrates the effect of changes in the taxation parameter.

These rates could be changed within a pay period or so for PAYE and indirect tax. Tax which is paid less frequently, such as provisional and company tax, could be adjusted pro rata for any period during which there was a change in the taxation parameter. (Pro-rata changes in the taxation parameter would create some scope for tax avoidance, but because changes in the parameter are unlikely to produce changes in the tax rate of more than a percentage point or two, this effect is unlikely to be major.) There would also be compliance costs involved in establishing such a system; but it does not seem to me that they would be large.

Table 1: The taxation parameter and tax rates $(\%)$

\begin{tabular}{ccccc}
\hline $\begin{array}{c}\text { Taxation } \\
\text { parameter }\end{array}$ & $\begin{array}{c}\text { Company } \\
\text { tax rate }\end{array}$ & $\begin{array}{c}\text { Income tax rate } \\
\text { below threshold }\end{array}$ & $\begin{array}{c}\text { Income tax rate above } \\
\text { tax-free threshold }\end{array}$ & $\begin{array}{c}\text { Sales } \\
\text { tax } \\
\text { rate }\end{array}$ \\
\hline 1 & 30 & 0 & 30 & 20 \\
.98 & 29.4 & 0 & 29.4 & 19.6 \\
1.02 & 30.6 & 0 & 30.6 & 20.4 \\
\hline
\end{tabular}

The setting of the fiscal parameter provides policy-makers with a mechanism for setting the stance of fiscal policy which is analogous to the setting of short-term interest rates. The extent to which the taxation parameter was set independently of government would then depend on the degree of control the CFA had over the parameter. The CFA could set the taxation parameter entirely independently of the government (presumably subject to performance goals set by government and/or the legislature). Alternatively, arrangements analogous to those under Sections 11(4) and (7) of the Reserve Bank Act could be made. Under such arrangements, the CFA could be free to set the parameter subject to some ultimate right of executive government to overrule it publicly with its own instructions.

Further, a narrow or a broad approach could be adopted in specifying the fiscal goals the CFA would be required to pursue. The CFA's task could be defined narrowly according to a fairly tightly defined rule or more broadly, according to a range of criteria. The first approach might see the CFA charged with the task of balancing the budget over the business cycle. The second approach could involve setting out a range of criteria for the CFA to consider, including for instance, the level of economic activity, the level of government net worth and the demands of intergenerational equity. To some extent, the choice between the two approaches mirrors the choice between rule-based and discretionary policy-making. The first option has more of the advantages of a rule, even though it allows for some discretion in the way the rule is satisfied. But it is also subject to some of the drawbacks of rules: for example, the rule involving budget balance over the cycle could allow a 
government to manipulate fiscal accounts in a variety of ways even with accrual accounting (Robinson, 1996:425).

These arrangements would not confine changes in fiscal policy to tax changes through changes in the taxation parameter. As is now the case with monetary policy, governments and central agencies would consult closely in bringing about mutually desired outcomes (Fraser, 1993). Thus, if a government wished to change the stance of fiscal policy by action on outlays rather than taxes, or preferred this to changes in the taxation parameter that the CFA thought were otherwise appropriate, it would inform the authority of this and so obviate the need for any tax changes. The government might also wish, for political or economic reasons, to amend the stance of fiscal policy with changes to certain taxes and not others; it could do this also by ensuring proper coordination with the CFA.

Although the CFA has been envisaged here as a new, separate agency, it would be important for fiscal policy and monetary policy to be integrated. In this regard, its functions would be well suited to the Reserve Bank (with any appropriate augmentation of the Bank's areas of professional expertise).

\section{Economic Consequences}

In several respects, the advantages of distancing the stance of fiscal policy from dayto-day government are analogous to the advantages of distancing monetary policy from governments. Assuming that, in principle, discretionary changes in the stance of policy can beneficially dampen the volatility of the business cycle, removing control from day-to-day government would enable policy to be adjusted to emerging economic circumstances more closely, more quickly, and more credibly. These points may be taken in turn.

First, the stance of fiscal policy could be more closely aligned to emerging economic circumstances because the CFA would be far more insulated from day-to-day party political concerns than governments of the day. Changes in the stance of fiscal policy invariably have political implications; and; certainly in Australia; it is common practice for changes in the stance of fiscal policy to reflect the undesirable influence of the short-term political impact of such measures.

Second, changes in fiscal policy must often be negotiated through legislatures. Of the discretionary fiscal expansions implemented as a response to recession in post-war America, none was finally enacted before the recession they were intended to address had technically ended (Keech, 1995:161ff). Institutional arrangements in Australia provide the executive with somewhat greater fiscal autonomy than this, but tax changes and various changes in outlays continue to require ratification from parliament, which delays their implementation.

Currently, monetary policy is the principal means by which governments seek to moderate the excesses of the business cycle, at least in the short term, not because monetary policy is inherently superior as a counter-cyclical instrument, but because institutional arrangements prevent rapid changes of fiscal policy. Indeed, if changes to the stance of fiscal policy could be implemented rapidly, they would have important advantages over monetary policy: they can influence the economy 
more quickly and in a less sector-specific way than monetary policy, which has very uneven effects concentrated in investment, capital-intensive consumption and traded-sector activity. Improving the timeliness of fiscal policy would thus make for more effective management of the business cycle. Fiscal policy could take substantial weight off monetary policy and broaden the base of counter-cyclical policy.

Third, as with monetary policy, greater policy independence could improve not only the policy settings chosen but also their effectiveness, by enhancing policy credibility. The cost of financing discretionary fiscal expansion would depend on the credibility of its officially temporary status. If lenders believe claims that fiscal expansion is temporary, they will be prepared to finance it at lower (interest) cost than if they expected expansion to be the prelude to higher government borrowing and indebtedness over the longer term. Greater credibility also enhances the speed with which policy changes can take effect as markets anticipate the effects of policy changes (Scott, 1995:7).

In this respect, the Australian monetary easings of August and November 1996 can be contrasted with the fiscal easing of February 1992. Other things being equal, an increase in short-term interest rates could be expected to raise long-term rates (by increasing the expected rate of growth and therefore inflation). Yet the monetary easings announced by the Reserve Bank in 1996 were greeted with falls in longterm rates: a sign of the market's confidence in the RBA's judgment that monetary easing was appropriate. Compare this with the nervousness of the money market about the modest fiscal expansion of February 1992. Certainly, other things being equal, a fiscal expansion could be expected to expand the government's call on borrowed funds and thus drive up bond rates; but had that expansion been sponsored by institutions at greater distance from party politics - institutions capable of reversing the expansion at a time they considered appropriate - the market is likely to have funded any given amount of fiscal expansion at lower interest cost than it did. Enhanced fiscal policy credibility would accordingly be likely to allow greater fiscal policy flexibility when it was needed.

\section{Political Consequences}

The arrangements discussed here would have somc interesting and salutary effects on the politics of fiscal policy. The structure of the tax system - for example, the extent to which revenue came from taxes on individuals' incomes, companies' incomes and consumption; the extent to which revenue was forgone in various tax concessions, and so forth - would continue to be determined politically; politicians would be frec to make whatever tax promises they wished to whomever they wished. But there would be important changes of emphasis. Under present monetary policy institutions, politicians routinely claim that their own party will deliver lower interest rates than their opponents. But they respect the institutions of independence by not promising that they will lower them directly under s.11 of the Reserve Bank $\Lambda$ ct, or that they will dismantle the institutions of monetary independence. This has a salutary effect: politicians who want to argue convincingly that interest rates will be lower under them must demonstrate that their policies would 
create the economic circumstances which would permit an independent expert body to ease monetary policy.

Mutatis mutandis, something similar can be expected in the area of fiscal policy. An independent body setting the stance of fiscal policy would make it harder for politicians to promise a tax cut without explaining how it will be funded. The existence of the CFA would shift the focus of attention to the capacity of a party's policies to deliver economic circumstances capable of allowing the desired tax cut. A party seeking to 'sell' a tax cut to the voters must also persuade them that it will be possible without an equal and opposite movement in other taxes - courtesy of the CFA mandating changes in the taxation parameter.

The CFA would enable politicians to rely less on what might be called 'populist fiscal rectitude' to counterbalance fiscal profligacy. My earlier claim that there may be an expansionist bias in democratic policy making is something of a simplification. The texture of politics seems undoubtedly to be expansionist in its smaller details: individual spending increases and tax reductions are almost invariably welcomed by the polity, their opposites regretted. Yet, where deficits mount, electors become sympathetic to political promises which offer solutions to this problem. In the United States, the fiscal anxiety of the electorate is underscored by the politics of balanced budget amendments. In Australia, the electorates' anxieties about fiscal profligacy have been addressed with targets such as the Hawke Government's 'trilogy' of fiscal commitments in 1984-87, and several State governments' mediumand long-term debt reduction targets. Much of this is a healthy reflection of the electorate's economic common sense. Certainly it has been the Australian experience that re-election to government is not incompatible with substantial fiscal tightening. ${ }^{3}$

Nevertheless, the arrangements set out here might offer some protection against the excesses of populist fiscal rectitude. For example, generally speaking, decisions on whether infrastructure assets should be privately or publicly owned should be made on the grounds of microeconomic efficiency and/or the effect of such decisions on government net worth. However well-meaning it might be, a commitment to reducing debt which does not pay full regard to the assets such debt may help fund and/or the capacity of those assets to service that debt tends to bias decisions about the ownership of assets away from the most important considerations. As the Auditor General of New South Wales has commented concerning the funding of the M2 motorway between Lane Cove and the Hills district of Sydney:

Here no public alternative to the private tollway was considered, because it was said the Treasury had no capacity to fund the motorway. This is decidedly odd reasoning. The private sector funded the road in

\footnotetext{
${ }^{3}$ For instance, the Hawke Government was retumed in 1987 after substantial fiscal tightening in 1986; and the Kennett Government was returned with a large majority in Victoria in 1996 after similarly tightening fiscal policy.
} 
anticipation of the stream of income it would produce. The same funding options were open to the Government. (Harris, 1997)

A CFA would be in a position to reassure not just financial markets but also the public that the government was not sliding towards an unsustainable or unhealthy debt position and that steps would be taken to resist any move in that direction. It is to be hoped that, in such circumstances, decisions about the ownership of infrastructure assets could focus more fully on the fundamentals of economic efficiency.

It might be argued that the arrangements set out here are less democratic than existing arrangements. In one sense, this is clearly true. The tax mix and the level of outlays and the particular programs which are supported by government would all be determined as before. But the determination of the overall stance of fiscal policy would be less directly democratic, in the same way that monetary policy and indeed judicial decisions are determined at one remove from the government of the day. The philosophical justification for this is analogous to the justification for constraining democracy in areas such as monetary policy or judicial decision making: that in such areas direct democracy can prejudice the interests of those without a vote (the young and subsequent generations) by debasing the currency and/or lead to the oppression of minorities.

On the other hand, the people appointed to make these decisions are in their turn appointed by a democratically elected assembly. As Ian Macfarlane (1996), Governor of the Reserve Bank of Australia, recently observed with regard to monetary policy independence, 'what usually goes under the rubric of ... independence' could be just as sensibly seen as 'a discussion of the optimal degree of delegation, including the circumstances in which the delegation could be withdrawn'. Recent experience might lead some to argue that government should delegate the stance of fiscal policy to a greater degree than it does at present.

\section{Potential Problems}

Such an important institutional reform as the establishment of a CFA would not be without its problems. Two are considered here.

First, although politicians are frequently blamed for 'short termism' in economic policy, they are in fact responding to popular pressure. The extent to which it is politically prudent to distance policy decisions from government is inevitably a matter of judgment. As notionally independent bodies are increasingly relied on to make or influence politically sensitive decisions, pressures can mount to make such bodies more 'responsive' and 'accountable' to community wishes. Governments will be tempted to appoint people to the 'independent' body who are sympathetic to their political objectives.

Second, it is possible that, despite their isolation from day-to-day politics and their professional expertise (or perhaps in some cases because of it), the staff of the independent agency could make worse decisions than politicians. Politicians may sometimes have an expansionist bias stemming from the incentives they face; but it 
is possible that the professional culture of the CFA could come to value fiscal conservatism too highly (see for example Krugman, 1996).

With these problems in mind the arrangements canvassed here are not offered as a panacea, largely for the same reasons that constitutionally entrenched fiscal rules should not be seen as a panacea. As the Australian Treasury (1995:3) has observed, 'responsibility, whether in fiscal policy or other matters, cannot be legislated into existence'. Rather than solving the dilemma which arises wherever politicians are tempted to buy short-term popularity by sacrificing longer-term prosperity, the arrangements set out here might help manage it by providing a new institutional structure through which that dilemma might be mediated.

Substantial tension could emerge between the CFA and the government of the day. In order to proceed cautiously, and with some of the potential problems enumerated above in mind, I would favour an arrangement whereby the government had the ultimate ability to overrule the CFA under provisions analogous to s.11 of the Reserve Bank Act. But experience in monetary policy has shown that, although they do not work miracles, such institutions can be a very useful influence on democratic policy making. Although the arrangements set out here cannot legislate responsibility into existence, they might help facilitate the development of a democratic culture of fiscal responsibility in the same way that similar arrangements have encouraged the emergence of a democratic culture of monetary responsibility over the last two decades.

\section{Postscript: Lawrence Ball's Proposed 'Macroeconomic Policy Committee'}

After submitting this article to Agenda, I became aware that Professor Lawrence Ball had made a similar proposal in a lecture he delivered in New Zealand in November 1996. Ball (1997) proposes a 'Macroeconomic Policy Committee' staffed with professionals who are independent of government. The committee would have power to direct the Reserve Bank on monetary policy and would control the stance of fiscal policy by making proportionate changes to tax rates.

The fact that such similar ideas were produced independently is a source of some reassurance as to their relevance. Nevertheless, it is worth exploring the differences between the two proposals. Ball's proposal stems from a desire to broaden the policy base of counter-cyclical policy by giving fiscal policy a larger role alongside monetary policy. My own proposal is more ambitious because, in addition to allowing fiscal policy to assume a greater role in managing the business cycle, it seeks to moderate the incentives which politicians face to sacrifice long-term prosperity for short-term political gain.

Ball suggests that the central agency have the power to change personal income taxes but not other taxes. Leaving indirect taxes out of the net seems sensible if the central purpose is to provide an instrument which can be deployed quickly to moderate inflationary pressures. (Increases in indirect tax will reduce demand but their first-round effect will be to raise prices and so exacerbate inflation.) However, it is not clear why Ball excludes company tax from the mechanism. My own intention in subjecting all major sources of taxation at a particular level of government to the 
taxation parameter was to make any change in the stance of fiscal policy as broadly based as possible. This is likely to have some economic merit, for the broader the base of fiscal discretion is, the less impact there will be on particular tax rates for any given fiscal effect. This limits the excess burden of taxation during fiscal contraction. However, the central attraction of broadening the base of discretionary fiscal policy is the political one of spreading fiscal sacrifice or largesse as widely as possible throughout the community. ${ }^{4}$

Second, Professor Ball (1997:7) proposes that 'the only role of the Macroeconomic Policy Committee would be to vary taxes temporarily, with increases and decreases canceling over time'. Certainly it would be desirable if this occurred; but the extent to which the Committee was remaining true to this policy at any given time would always be somewhat unclear because judgments would have to be made about the likely duration of any particular upswing or downturn which the Committee was seeking to moderate. But, however much one might want the Macroeconomic Policy Committee's fiscal adjustments to be temporary and counterbalancing, it must be understood how powerful a constraint this could be. Professor Ball's discussion of the problem of fiscal policy focuses entirely on the difficulty of timing fiscal policy given current institutions. My own exposition argues that there are two current problems with existing institutions: one of timing and one of a secular expansionist bias. Imagine a situation in which a government expanded fiscal policy in a manner which the Macroeconomic Policy Committee considered irresponsible. This places the Committee in an invidious position. Any resort to fiscal policy tightening in such a situation is likely to place it in a difficult situation subsequently. For at some point after it tightens fiscal policy the Committee can expect to face a situation in which it must loosen fiscal policy and lower taxes in order to honour its charter to balance its fiscal policy corrections through the cycle. This seems unsatisfactory.

In not embracing the constraint Professor Ball proposes, I hope that my proposed arrangements can address both problems. That said, it would probably be a mistake to be too categorical. Arguably, my proposals make the CFA bite off more than it can reasonably be expected to chew: that any government prepared to expand fiscal policy for electoral advantage would have few qualms about subverting

\footnotetext{
${ }^{4}$ That said, there are some quite good arguments against including indirect taxes in the taxation parameter mechanism. First, governments could come under pressure to make adjustments to welfare benefits when the fiscal parameter produced an increase in indirect tax. Second, anticipated changes to indirect taxes can produce perverse results where changes in indirect tax rates are implemented for counter-cyclical reasons. Thus, if people suspected an indirect tax rise was imminent because of inflationary pressures, some would bring forward purchases, thus exacerbating those pressures. The opposite would happen when a tax cut was expected. Nevertheless, the changes to tax rates anticipated here will be small - of the order of one or two percentage points to tax rates at any one time - and so one might expect the forward-pull and back-pull of demand to be similarly modest. If these arguments were considered sufficient to exclude indirect taxation from the taxation parameter arrangements, it still seems both economically and politically worthwhile to make the net of fiscal discretion as wide as possible and so to include corporate as well as personal income taxation.
} 
the CFA either by directing it (if it had the power to) or appointing sympathetic persomnel to it (if it did not). If this argument were accepted, the CFA might find that its power as a countervailing force against fiscal expansion existed de jure but not de facto. So the two proposals may not be far apart.

Yet this conclusion seems to me too pessimistic, and also inconsistent with our experience of monetary policy management over the last two decades. There would have been many occasions when it might have been expected that the Australian government would use s.11 of the Reserve Bank Act to direct the Bank. In practice it never has. Nor has a Governor ever been appointed to the Bank who was a mere political servant of the government. These facts tip the balance, I believe, towards a more rather than less ambitious proposal. Judgments would no doubt differ, but the institutional arrangements I have proposed offer the advantages of those offered by Professor Ball at the same time as providing an institutional framework which could make a major contribution towards the development of a democratic culture of fiscal responsibility.

\section{References}

Ball, L. (1997), 'A Proposal for the next Macroeconomic Reform', Victoria Economic Commentaries 14(1): 1.7 (VUW Foundation Lecture, 11 November 1996).

Blinder, A. \& R. Solow (1974), 'The Analytical Foundations of Fiscal Policy', pp. 3-11 in A. Blinder, R. Solow, G. Break, P. Steiner \& R. Netzer, The Economics of Public Finance, Brookings Institution, Washington DC.

Bollard, A. (1994), 'The Fiscal Responsibility Bill: Fiscal Policy', Public Sector 17(1): 11-12.

Commonwealth Treasury (1995), 'Treasury Submission to the Joint Committee of Public Accounts inquiry into Fiscal Responsibility Legislation', Economic Roundup, Spring.

Fraser, B. (1993), 'Some Aspects of Monetary Policy', Reserve Bank Bulletin, April: 1-7.

Harris, A. (1997), 'Privatisation: The Role of Public Sector Auditors', seminar given to the Economic Society of Australia, New South Wales Branch (5 February).

Keech, W. (1985), 'A Theoretical Analysis of the Case for a Balanced Budget Amendment', Policy Sciences 18: 157-68.

— (1995), Economic Politics: The Costs of Democracy, Cambridge University Press, Cambridge.

Krugman, P. 1996), 'Stable Prices and Fast Growth: Just Say No', Economist, 31 August: 15-18.

Macfarlane, I. (1996), 'Making Monetary Policy: Perceptions and Reality', talk delivered to 25th Conference of Economists, Australian National University, 25th September (mimeo).

Richardson, R. (1994), 'Comment on the Fiscal Responsibility Bill', Public Sector 17(1): 10-11.

Robinson, M. (1996), 'Can Fiscal Responsibility Legislation be Made to Work', Agenda 3: 419-30.

Scot, G. (1995), 'New Zealand's Fiscal Responsibility Act', Agenda 2(1): 3-16.

The author is grateful for comments on a previous draft of this article from Fred Argy, Robert Albon, Lawrence Ball, Vince FitzGerald, David Gruen, Fred Gruen, Tony Harris, William Keech, John Phillips, Marc Robinson, Sue Richardson, Bill Scales and two anonymous referees. 